\title{
Correction to: Introduction to Transport Phenomena Modeling
}

\section{Correction to: \\ G. Ruocco, Introduction to Transport Phenomena Modeling, https://doi.org/10.1007/978-3-319-66822-2}

In the original version of the book, the belated corrections from author for Chaps. 2-6 should be incorporated. The correction book has been updated with the changes.

\footnotetext{
The updated version of these chapters can be found at https://doi.org/10.1007/978-3-319-66822-2_2 https://doi.org/10.1007/978-3-319-66822-2_3 https://doi.org/10.1007/978-3-319-66822-2_4 https://doi.org/10.1007/978-3-319-66822-2_5 https://doi.org/10.1007/978-3-319-66822-2_6 